\title{
AUTOMATED ELISA FOR DIRECT MEASUREMENT OF FREE 25OH VITAMIN D
}

\author{
L.M. Swinkels, T. Huijs, M. Geurts, E. Lindhout, N. Heureux*, M. Martens.
}

Future Diagnostics Solutions B.V., Wijchen, The Netherlands, *DIAsource Immunoassays, Louvain-la-Neuve, Belgium.

\section{Introduction}

Recent studies suggest that the concentration and genotype of Vitamin D binding protein (DBP) are important factors that determine the bioavailability of $25 \mathrm{OH}$ Vit $\mathrm{D}$ in blood. It has been suggested that measurement of free, non-protein bound $250 \mathrm{H}$ Vit $\mathrm{D}$ in serum, may provide more relevant diagnostic information than total $250 \mathrm{H}$ Vit $\mathrm{D}$, for instance in chronic kidney disease, bladder cancer and pancreatic cancer, or in hemodialysis patients ${ }^{1-9}$. To measure Free $250 \mathrm{H}$ Vit $\mathrm{D}$ in blood Future Diagnostics developed a direct ELISA method. Following the first laboratory evaluation phase, a two-step enzyme-linked immunosorbent assay (ELISA) was optimized for the quantification of free $250 \mathrm{H}$ Vit-D assay ${ }^{10,11}$. Modifications were made in the protocol for the coating of the monoclonal anti-25OH Vit-D in the microtiter plates as well as in the formulation of the sample diluent and of the biotinylated Vitamin D conjugate. The optimized assay was validated and showed the following performances: the calibrator range is $0.2-35 \mathrm{pg} / \mathrm{ml}$. Total assay precision is $10.2 \%$ at $6.0 \mathrm{pg} / \mathrm{ml}, 7.6 \%$ at $10.9 \mathrm{pg} / \mathrm{ml}$ and $5.5 \%$ at $24.9 \mathrm{pg} / \mathrm{ml}$. The crossreactivity of the antibody towards $25 \mathrm{OH}$ Vitamin D2 is $77 \%$ and the influence of interfering hemoglobin, bilirubin and triglycerides was also verified being lower than $10 \%$. Additional experiments have shown that the addition of albumin or Vitamin D Binding Protein to serum leads to a decrease in the observed level of free $250 \mathrm{H}$ Vit-D.

\begin{tabular}{|c|c|c|}
\hline Sample & \multicolumn{2}{|c|}{ Free 250H Vitamin D $(\mathbf{p g} / \mathbf{m L})$} \\
\hline & Native & Spiked with DBP $2 \mathrm{mg} / \mathrm{mL}$ \\
\hline Sample 1 & 9.74 & 3.49 \\
\hline Sample 2 & 8.09 & 3.08 \\
\hline Sample 3 & 11.98 & 4.18 \\
\hline & Native & 9.41 \\
\hline Sample 4 & 17.87 & 5.83 \\
\hline Sample 5 & 9.99 & 6.14 \\
\hline Sample 6 & 10.93 & Spiked with HSA 60g/L \\
\hline
\end{tabular}

Here we describe the comparison between automated and manual processing of the ELISA for measuring Free 250H Vitamin D.

\section{Methods}

The principle of the assay. During the first incubation step free $250 \mathrm{H}$ Vitamin D binds to the monoclonal anti-Vitamin $\mathrm{D}$ in the microtiter plate. The in vivo equilibrium between free and bound $250 \mathrm{OH}$ Vitamin D is minimally disturbed by the use of a specific displacement reagent. After washing, a fixed amount of biotinylated $250 \mathrm{H}$ Vitamin $\mathrm{D}$ is added to each well. The non-bound biotinylated $250 H$ Vitamin $D$ is removed by washing and a streptavidin peroxidase conjugate is added. In the next step TMB substrate is added. Next the reaction is stopped and the absorbance is measured using a plate reader.

\section{Protocol Manual}

- Add $90 \mu \mathrm{L}$ of sample diluent into the wells.

Add $10 \mu$ l samples into the well.

Incubate shaking (orbital) 90 min at $37^{\circ} \mathrm{C}$ Wash

Add $100 \mu \mathrm{L}$ biotin-25(OH) VitD into each well.

Incubate shaking (orbital) $30 \mathrm{~min}$ at $37^{\circ} \mathrm{C}$

Wash

Add $100 \mu \mathrm{L}$ of strep-HRP into each well

Incubate shaking (orbital) for $20 \mathrm{~min}$ at $37^{\circ} \mathrm{C}$ Wash

Add $100 \mu \mathrm{L}$ of TMB substrate into each well. Incubate 15 minutes at RT in the dark.

Add $100 \mu \mathrm{L}$ Stop Solution into each well.

Read the absorbance at $450 \mathrm{~nm}$.

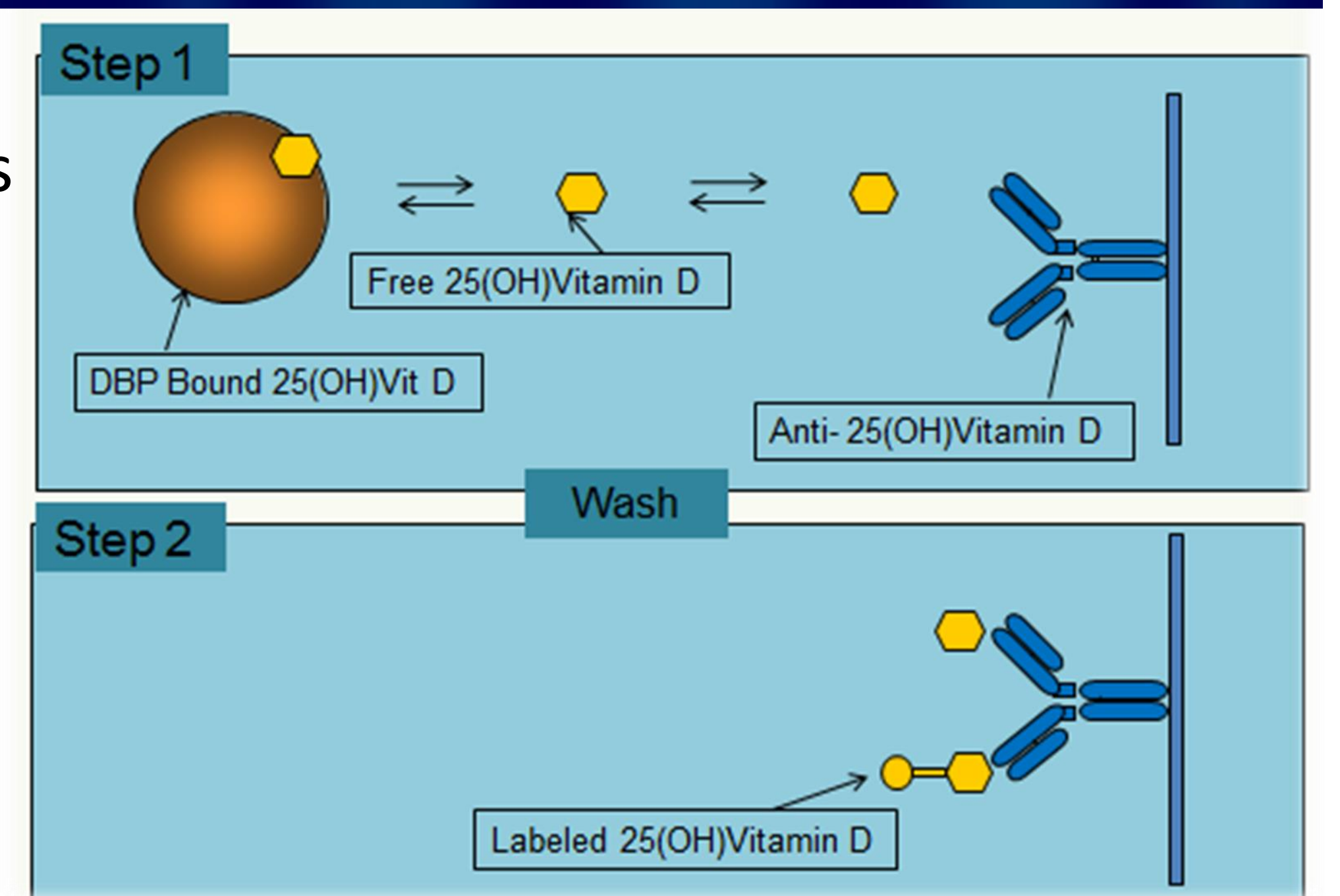

rotocol Dynex DS2

- Add $90 \mu$ l of sample diluent into the wells.

- Add $10 \mu$ l sample in to the well.

Incubate shaking(linear) $90 \mathrm{~min}$ at $37^{\circ} \mathrm{C}$ Wash

Add $100 \mu$ l biotin-25(OH) VitD into each well Incubate shaking (linear) $30 \mathrm{~min}$ at $37^{\circ} \mathrm{C}$. Wash

Add $100 \mu \mathrm{L}$ of strep-HRP into each well.

Incubate shaking (linear) for $20 \mathrm{~min}$ at $37^{\circ} \mathrm{C}$ Wash

Add $100 \mu \mathrm{L}$ of TMB substrate into each well. - Incubate 15 minutes at RT in the dark.

Add $100 \mu \mathrm{L}$ Stop Solution into each well.

Shake 5 seconds.

Read the absorbance at $450 \mathrm{~nm}$

\section{Literature references}

'Haddad J.G. The Vitamin D binding Protein and its clinical significance. In: Vitamin D: physiology, molecular biology and clinical applications. 1999, 101-107.

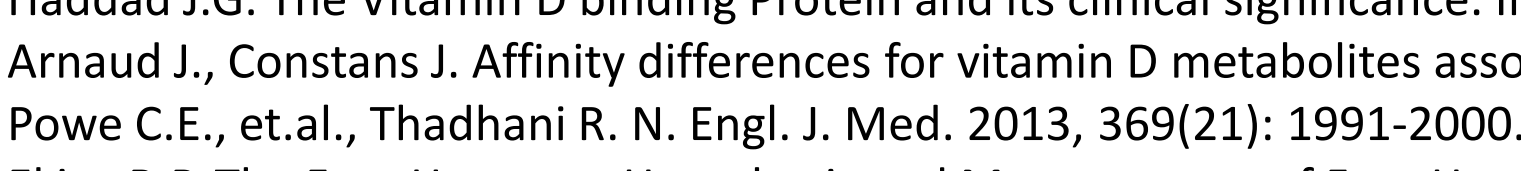

\section{Results}

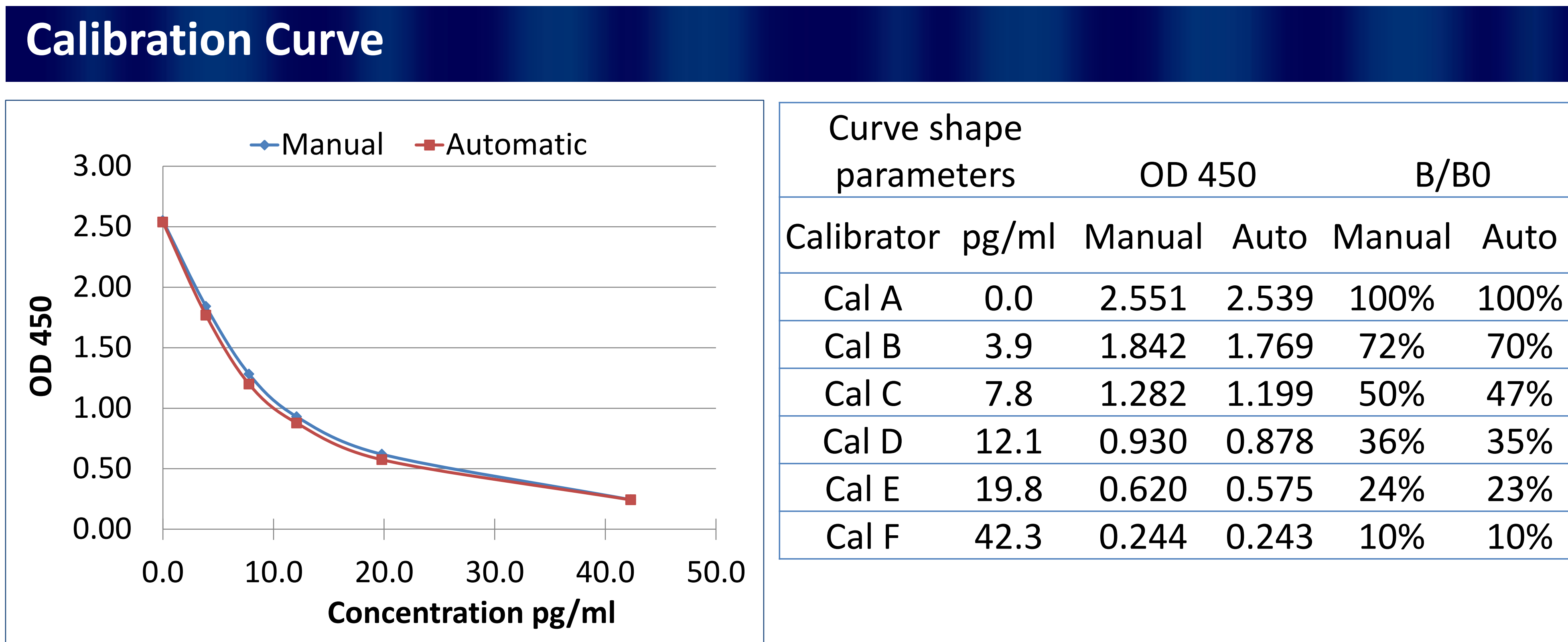

\section{Limit of Blank \& Limit of Detection}

The LoB and LoD in $\mathrm{pg} / \mathrm{mL}$ were determined according to CLSI EP17-A2. For LoB 38 reps were measured. For LOD $4 * 38$ reps were measured.

\begin{tabular}{|lrr|}
\hline & Manual & Automated \\
\hline LoB & 0.96 & 0.52 \\
\hline LoD & 1.83 & 1.28 \\
\hline
\end{tabular}

\section{Control samples - Precision}

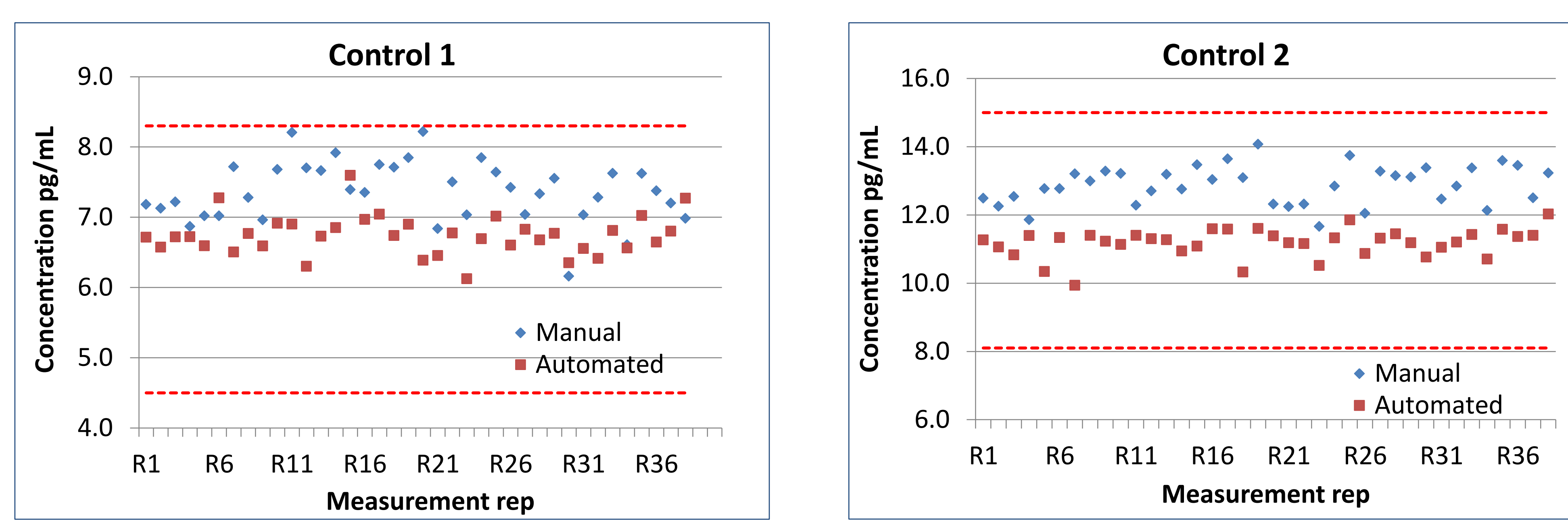

\begin{tabular}{|rccc|}
\hline \multicolumn{1}{|l}{ Control 1 } & & & \\
\hline & Mean & SD & CV \\
\hline Manual & 7.37 & 0.43 & $5.8 \%$ \\
\hline Automated & 6.74 & 0.28 & $4.2 \%$ \\
\hline
\end{tabular}

Control 2 Measurement rep

\section{Sample correlation}

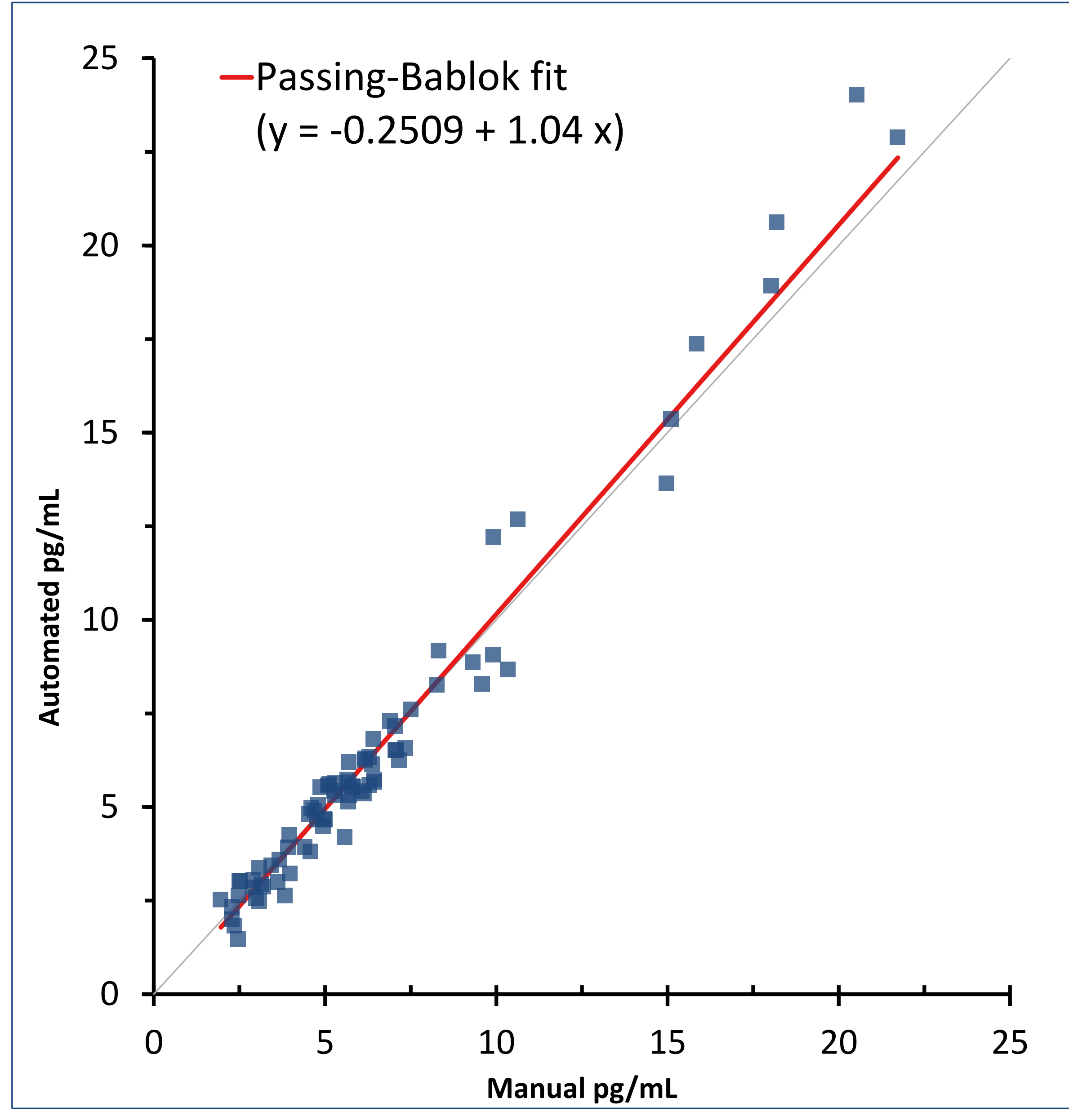

In total 78 random samples were measured in the manual and in the automated assay. The slope, intercept and $r$ show substantial equivalency between the manual and automated performed assay.

Correlation

Pearson's $r$ 0.986 Fisher $95 \% \mathrm{Cl} \quad 0.979$ to 0.991

\section{Conclusion}

The Free $250 \mathrm{H}$ Vit-D assay that reproducibly determines the level of Free $250 \mathrm{H}$ Vit $D$ in serum was validated on an open ELISA platform. The manual and automated results were compared in terms of Dose response curve, LoB, LoD, Precision, and Correlation and show substantial equivalency.

The Free $250 \mathrm{OH}$ Vitamin-D ELISA eliminates the need to calculate the bioavailable 250 H Vitamin D from the measured DBP, HSA and total Vit-D concentrations. 


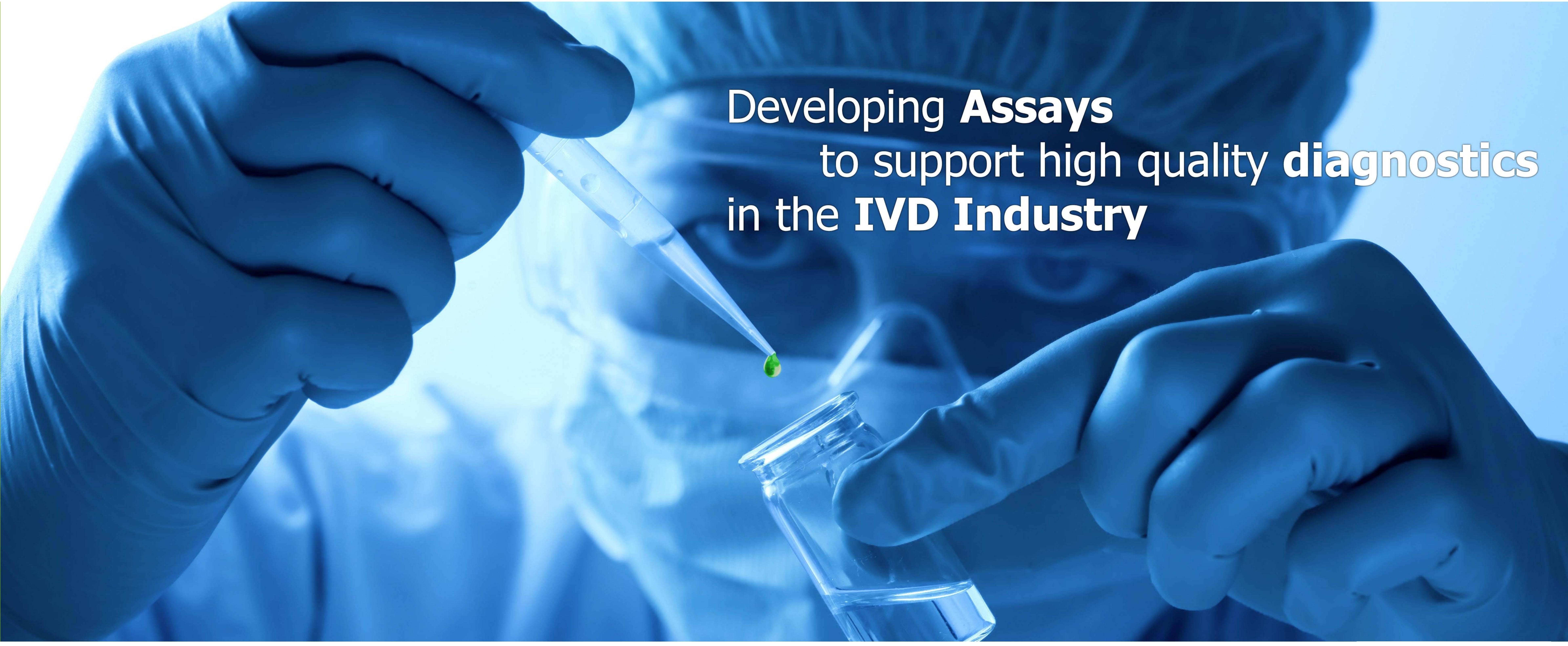

Visit us at www.Future-diagnostics.com

Future Diagnostics Solutions Free 250H Vitamin D assay. Why calculate when you can measure?
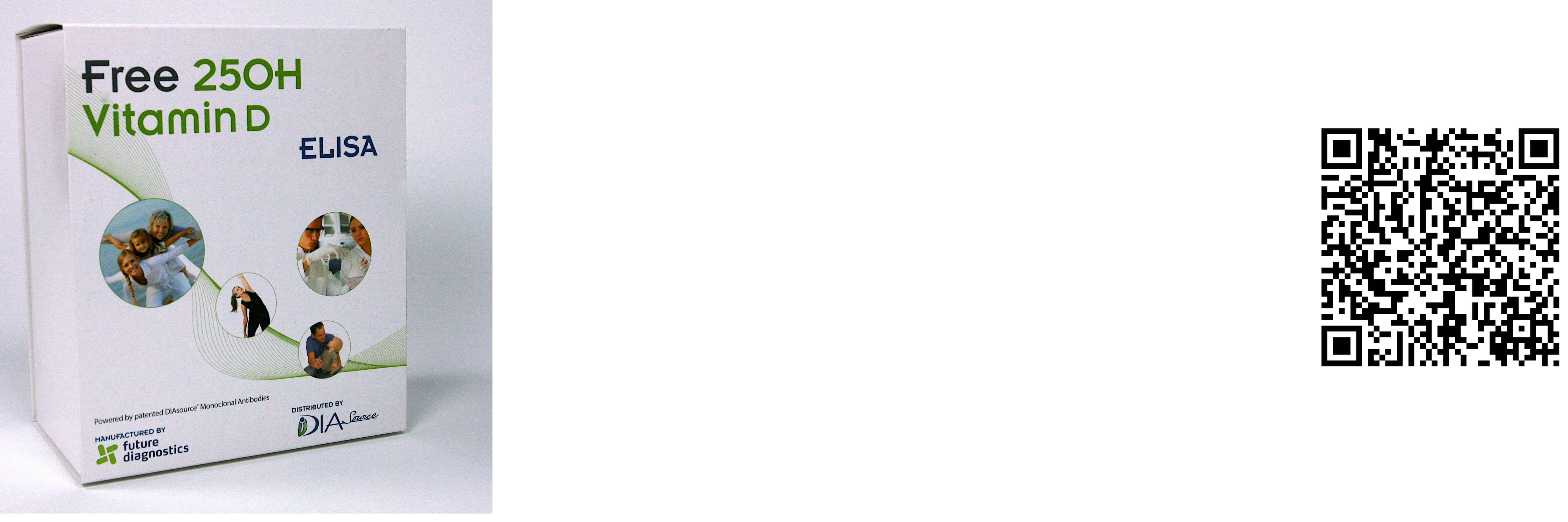

Future Diagnostics Solutions Intra Operative-intact-PTH assay. It's more than saving time
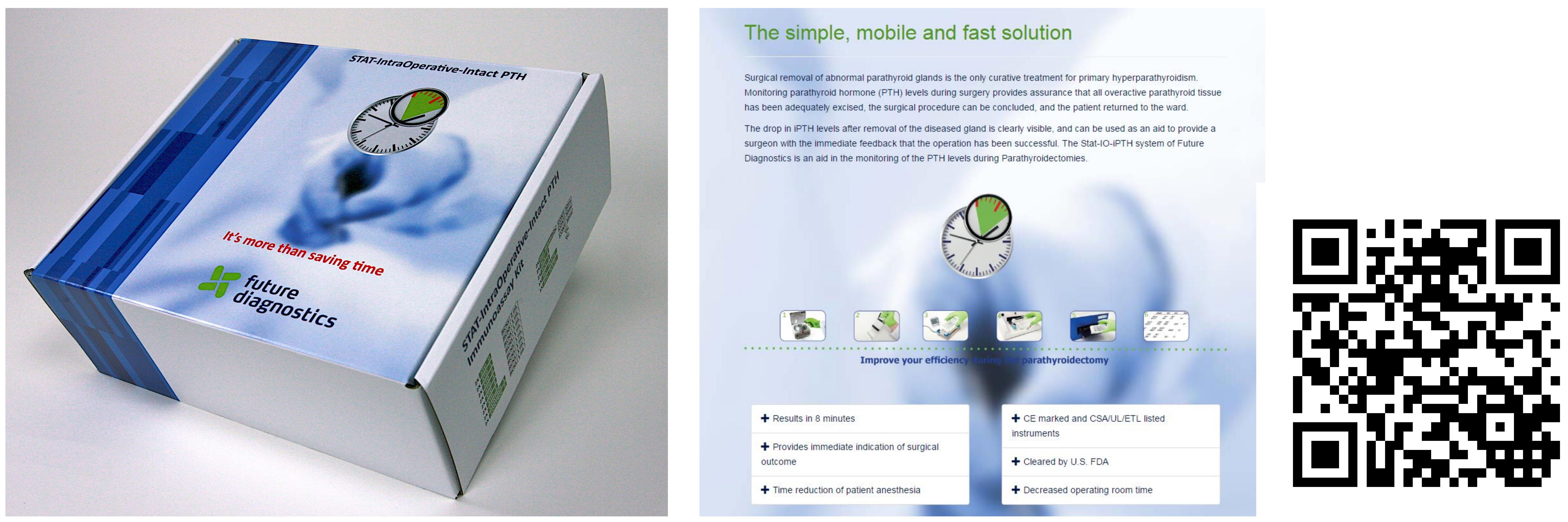